Article

\title{
Increasing Mechanical Properties of 2-D-Structured Electrospun Nylon 6 Non-Woven Fiber Mats
}

\author{
Chunhui Xiang ${ }^{1, *}$ and Margaret W. Frey ${ }^{2}$ \\ 1 Department of Apparel, Events and Hospitality Management, Iowa State University, Ames, IA 50011, USA \\ 2 Department of Fiber Science and Apparel Design, Cornell University, Ithaca, NY 14853, USA; \\ mfw24@cornell.edu \\ * Correspondence: chxiang@iastate.edu; Tel.: +1-515-294-7515
}

Academic Editor: Armando J. D. Silvestre

Received: 30 December 2015; Accepted: 29 March 2016; Published: 7 April 2016

\begin{abstract}
Tensile strength, Young's modulus, and toughness of electrospun nylon 6 non-woven fiber mats were improved by increasing individual nanofiber strength and fiber-fiber load sharing. Single-walled carbon nanotubes (CNTs) were used as reinforcement to increase the strength of the electrospun nylon 6 nanofibers. Young's modulus, tensile strength, and toughness of the nylon 6 non-woven fiber mats electrospun from $20 \mathrm{wt} \%$ solutions increased $51 \%, 87 \%$, and $136 \%$, respectively, after incorporating $1 \mathrm{wt} \%$ CNTs into the nylon 6 nanofibers. Three methods were investigated to enhance fiber-fiber load sharing: increasing friction between fibers, thermal bonding, and solvent bonding. The addition of beaded nylon 6 nanofibers into the non-woven fiber mats to increase fiber-fiber friction resulted in a statistically significantly increase in Young's modulus over comparable smooth non-woven fiber mats. After annealing, tensile strength, elongation, and toughness of the nylon 6 non-woven fiber mats electrospun from $20 \mathrm{wt} \%+10 \mathrm{wt} \%$ solutions increased $26 \%, 28 \%$, and $68 \%$ compared to those from $20 \mathrm{wt} \%$ solutions. Solvent bonding with formic acid vapor at room temperature for $30 \mathrm{~min}$ caused increases of $56 \%, 67 \%$, and 39\% in the Young's modulus, tensile strength, and toughness of non-woven fiber mats, respectively. The increases attributed to increased individual nanofiber strength and solvent bonding synergistically resulted in the improvement of Young's modulus of the electrospun nylon 6 non-woven fiber mats.
\end{abstract}

Keywords: increasing; electrospun; nylon 6; mechanical properties; 2-D structure; solvent bonding; annealing; solvent vapor exposure; non-woven fiber mats

\section{Introduction}

Electrospinning can produce polymer fibers with diameters in the range of nanometers to a few micrometers. The electrospun nanofibers have many potential applications such as optical materials [1], sensor materials [2], nanocomposite materials [3], tissue scaffolds [4], wound dressing [5], drug delivery systems [6], filtration [7], and protective clothing [8]. However, because electrospun fiber mats have very poor mechanical properties due to the random orientation within the fibers and broad distribution of fiber diameter, their actual uses have been limited. Hence, an enhancement in mechanical properties of the electrospun fiber mats is very important from an industrial point of view [9].

Mechanisms of deformation in non-woven fabrics are based on fiber and bond deformations [10]. The inherent strength of fibers produced by electrospinning is dependent on polymer type, crystallization rate, and degree of crystallinity. Nylon 6 has a rapid crystallization rate and has been shown to produce strong electrospun fibers [11]. Due to this property, nylon 6 is often used in industry as a coating for filter media [12]. Park et al. [9] suggested the combined effects of the higher degree alignment, the surface nanocoating, and the formation of internal networks of polyelectrolytes on nylon-6 fibers resulted in higher tensile strength. Papkov et al. [13] has demonstrated improvements 
in modulus and strength of individual electrospun polymer nanofibers with a reduction in their fiber diameter. They reported that reduction of fiber diameter resulted in simultaneous increases in elastic modulus, true strength, and toughness.

Kim et al. [14] reported that the electrospun thermoplastic polyurethane elastomer (TPU) fiber mats showed nonlinear elastic and inelastic characteristics, which might be due to slippage of crossed fiber (nonbonded or physical bonded structure) and breakage of the electrospun fibers at junctions (point-bonded or chemical bonding structure) and demonstrated that the point-bonded structures of fiber mats played an important role in the load-bearing component as determined in loading-unloading component tests.

Theoretical and experimental studies have shown that carbon nanotubes (CNTs) have an extremely high Young's modulus, similar to that of the in-plane value for graphite ( 1000 GPa) [15]. CNTs are considered to be the ideal reinforcing agent for high-strength polymer composites, because of their high mechanical strength, electrical conductivity, and thermal conductivity. Good interfacial adhesion between the CNTs and the polymer matrix is essential for efficient load transfer in the composite [16]. CNTs are often used as a reinforcing phase to improve mechanical properties of fibers by: (a) acting as a physical reinforcement; and (b) acting as a nucleation agent to increase overall crystallinity of fibers. Therefore, CNT-reinforced polymer composites have potential applications in defense and aerospace applications, where high-strength and light-weight components are of primary importance. Many polymers are presently being investigated as host matrices for CNTs, and the resulting composites have been found to show improved mechanical properties. A direct mixing of multiwalled carbon nanotubes (MWNTs) and polystyrene led to a $36 \%-42 \%$ increase in elastic stiffness and a $25 \%$ increase in tensile strength with the incorporation of only $1 \mathrm{wt} \%$ of MWNTs into the polystyrene matrix [17]. Mahfuz et al. [18] reported that tensile tests on single nylon 6 filmaments had demonstrated that Young's modulus and strength of the nanophased filaments had increased by $220 \%$ and $164 \%$ with the addition of $1 \mathrm{wt} \%$ of MWNTS. In addition to the strength of individual fibers, the number of crossings per nanofiber, intersections per unit area, total nanofiber crossings in the mat, and three-dimensional joint morphology all play an important role in the mechanical properties of non-woven nanofiber mats [19]. Nylon 6 is of significantly industrial importance because of its excellent strength, toughness, and wearing resistance [11,15].

In the present study, single-walled carbon nanotubes (CNTs) were incorporated into the nylon 6 nanofibers during electrospinning to increase the individual fiber strength. Beaded electrospun nylon 6 fibers were introduced to uniform nylon 6 nanofiber non-woven fiber mats to increase fiber-fiber bonding and hence to improve the mechanical properties of 2-D-structured electrospun nylon 6 non-woven fiber mats. The as-spun nylon 6 non-woven fiber mats were also exposed over formic acid vapor at room temperature to increase fiber-fiber bonding.

\section{Results and Discussion}

\subsection{Increase Nylon 6 Nanofiber Strength}

Figure 1 shows the typical stress-strain plots of nylon 6 non-woven fiber mats electrospun from $20 \mathrm{wt} \%$ nylon 6 in $88 \%$ formic acid solutions with and without $1 \mathrm{wt} \%$ (based on the weight of nylon 6) CNTs. Table 1 is the summary of the tensile properties of nylon 6 non-woven fiber mats electrospun from $20 \mathrm{wt} \%$ nylon 6 in $88 \%$ formic acid solutions with and without $1 \mathrm{wt} \%$ CNTs. Young's modulus, tensile strength, elongation, and toughness (calculated by integrating the area under the stress-strain curves) of the nylon 6 non-woven fiber mats increased 51\%,87\%, 18\%, and 136\%, respectively, after incorporating $1 \mathrm{wt} \%$ CNTs into the nylon 6 nanofibers. Therefore, the composite electrospun nylon 6/CNTs non-woven fiber mats have a higher stiffness, strength, and ductility. The enhancement in the mechanical properties might originate from the good dispersion of CNTs as well as the strong interaction between CNTs and nanofibers. Good interfacial adhesion between the CNTs and the nylon 6 nanofiber is essential for efficient load transfer in the non-woven fiber mats [16]. 
The improvement of the strength property by incorporating CNTs into the nanofibers was expected and consistent with the reported results in the literature. Bazbouz et al. [19] reported that the tensile strength of the nylon 6 nanofiber mats electrospun from $20 \mathrm{wt} \%$ containing only $1.0 \mathrm{wt} \%$ MWCNTs (Multiwall carbon nanotubes) was increased by 25\%, compared with the nylon 6 mats. They also reported that the strain at break (elongation) of the nylon 6/MWCNTs nanofiber mats was decreased by $18 \%$. However, the elongation of the electrospun nylon $6 /$ SWNTs non-woven fabrics increased $18 \%$. Jeong et al. [20] reported the elongation of electrospun polyvinyl alcohol (PVA) non-woven fabrics increased by incorporating MWNTs into composite nanofibers when the weight percentage of filler (MWNTs) was lower than $3 \mathrm{wt} \%$. The reason for this is that, at a low filler wt \%, the load transfer to the inner nanotubes is low, which enhances the tensile properties. The initial increase in the tensile strength and tensile modulus (i.e., for the composites containing $1 \mathrm{wt} \%$ and $2.5 \mathrm{wt} \%$ of filler) is attributed to the high degree of orientation of the filler nanotubes in the wrapped nanofibers.

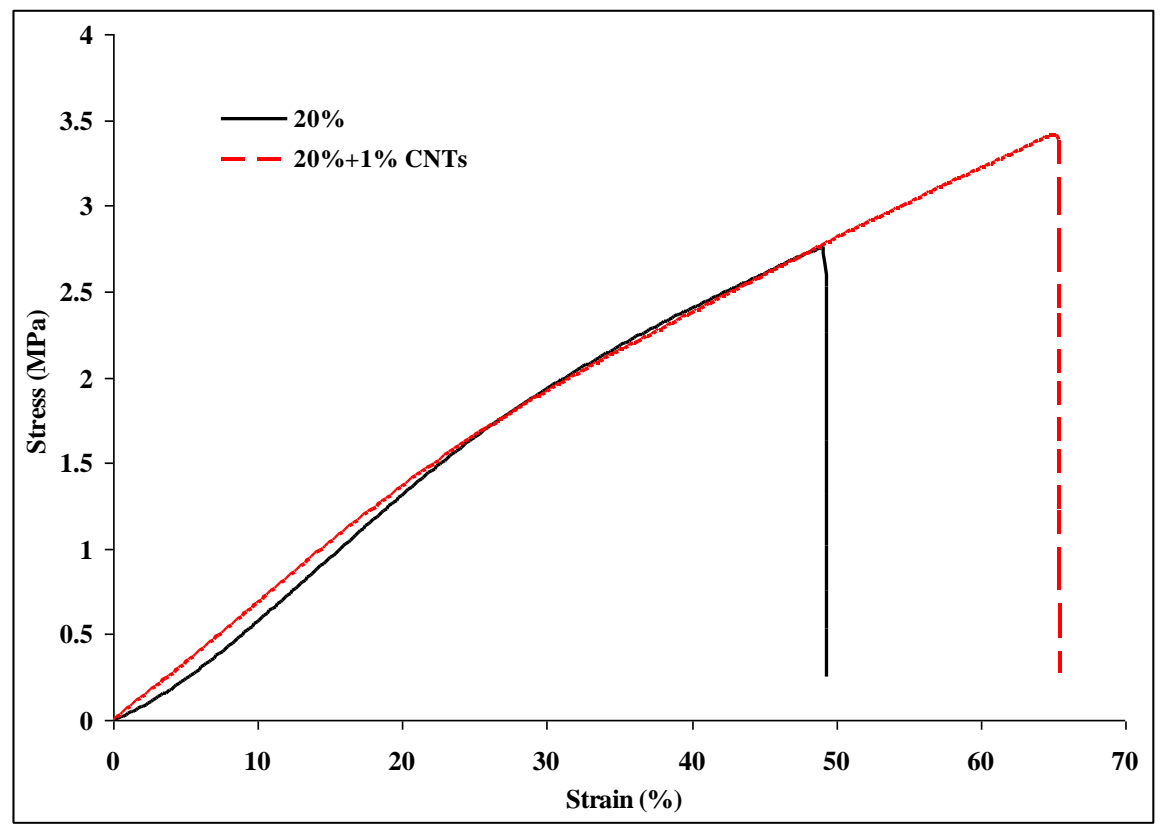

Figure 1. Typical stress-strain plots of nylon 6 non-woven fiber mats electrospun from $20 \mathrm{wt} \%$ nylon 6 solutions with and without $1 \mathrm{wt} \%$ carbon nanotubes (CNTs) suspensions.

Table 1. Tensile properties of nylon 6 non-woven fiber mats electrospun from $20 \mathrm{wt} \%$ nylon 6 with/without CNTs.

\begin{tabular}{ccc}
\hline Tensile Properties & $\mathbf{2 0} \%$ & $\mathbf{2 0} \% \mathbf{+ 1 \%}$ CNTs \\
\hline Young's modulus $(\mathrm{MPa})$ & $4.81 \pm 1.03$ & $7.25 \pm 1.96$ \\
Tensile strength $(\mathrm{MPa})$ & $2.03 \pm 0.99$ & $3.80 \pm 1.87$ \\
Elongation $(\%)$ & $54.1 \pm 14.6$ & $63.7 \pm 19.2$ \\
Toughness $(\mathrm{MPa})$ & $0.64 \pm 0.48$ & $1.51 \pm 1.05$ \\
\hline
\end{tabular}

\subsection{Increase Fiber-Fiber Bonding}

\subsubsection{Beaded Fiber Effect}

In order to improve the mechanical stability of the electrospun nanofibrous mat, the interfiber bonding could be introduced by controlling the electrospinning process or by post-processing. If a spinning solvent has relatively low volatility (a high boiling point), a considerable amount of solvent remains within nanofibers deposited on target, and wet fibers are then formed. The presence of residual solvent in the electrospun nanofiber facilitates the bonding of intersecting fibers [21]. Figure 2 
shows the morphology of nylon 6 non-woven fiber mats electrospun from $20 \mathrm{wt} \%, 10 \mathrm{wt} \%$, and $20 \mathrm{wt} \%$ paralleled with $10 \mathrm{wt} \%$ solutions. Nylon 6 nanofibers electrospun from $20 \mathrm{wt} \%$ solutions (Figure 2a) have uniform fiber diameters, while nylon 6 nanofibers electrospun from 10 wt \% solutions (Figure $2 \mathrm{~b}$ ) shows a highly beaded structure. Therefore, the non-woven fiber mats produced by paralleled electrospinning $20 \mathrm{wt} \%$ and $10 \mathrm{wt} \%$ solutions resulted in a combination of uniform fibers and beaded fibers (Figure 2c). With the addition of the beaded nylon 6 nanofibers into the non-woven fiber mats, the nylon 6 non-woven fiber mats electrospun from $20 \mathrm{wt} \%$ and $10 \mathrm{wt} \%$ demonstrated a statistically significant increase in Young's modulus when compared with nylon 6 non-woven fiber mats electrospun from $20 \mathrm{wt} \%$ (Figure 3). Formic acid has a boiling point of $101^{\circ} \mathrm{C}$, which is relatively low volatility. The addition of beaded nylon 6 nanofibers into the comparable smooth non-woven fiber mats resulted in the increase of fiber-fiber friction.

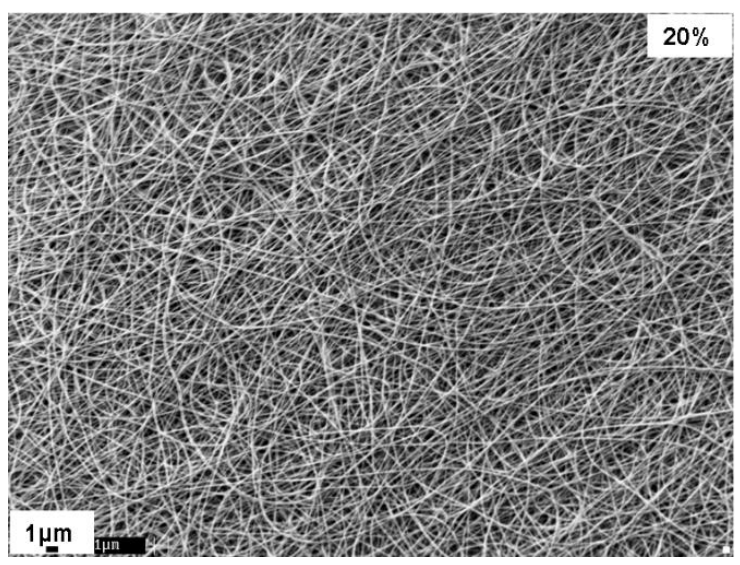

(a)

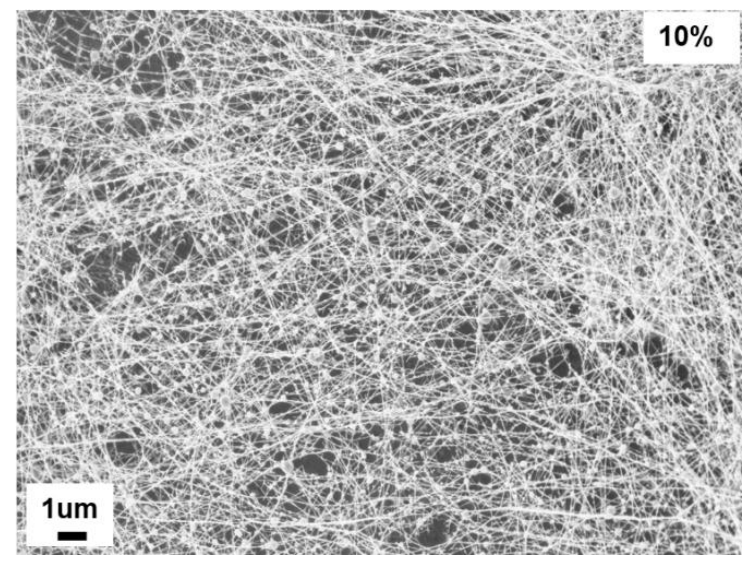

(b)

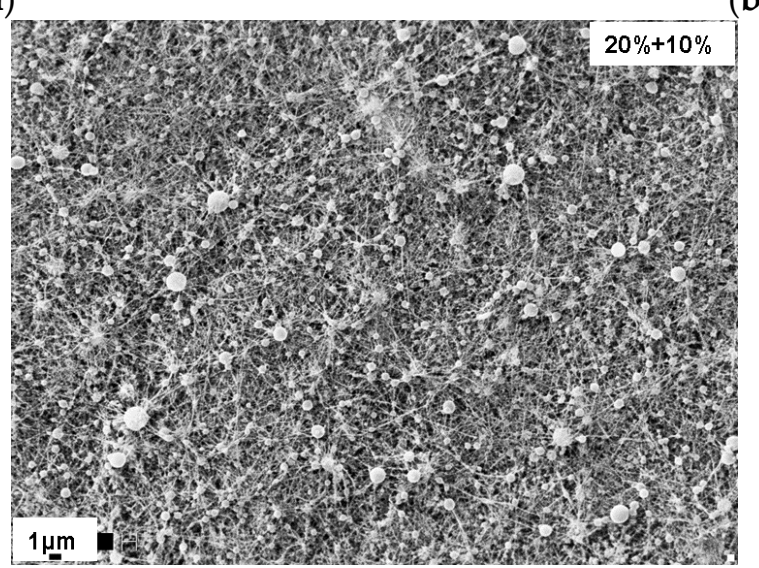

(c)

Figure 2. SEM imaging of nylon 6 nanofibers electrospun from (a) $20 \mathrm{wt} \%$ nylon 6; (b) $10 \mathrm{wt} \%$ nylon 6; and (c) $20 \mathrm{wt} \%$ and $10 \mathrm{wt} \%$ in $88 \%$ formic acid solutions. 


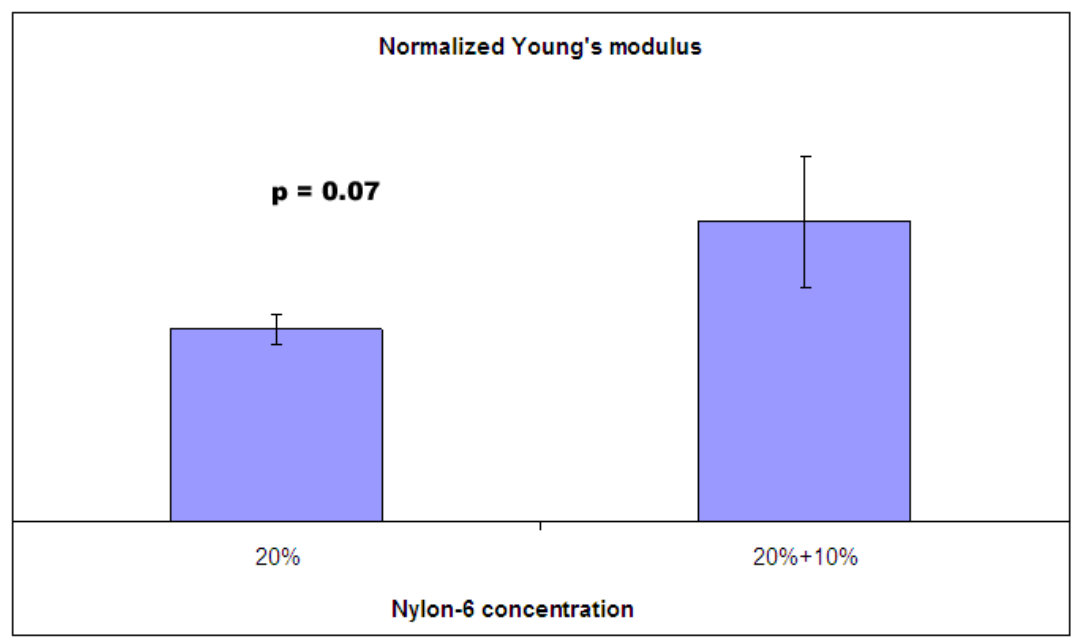

Figure 3. Beads effect on Young's modulus of electrospun nylon 6 non-woven fiber mats.

\subsubsection{Annealing Nylon 6 Non-Woven Fiber Mats}

Figure 4 shows the typical stress-strain plots of nylon 6 non-woven fiber mats electrospun from $20 \mathrm{wt} \%$ and $10 \mathrm{wt} \%$ solutions. After annealing, tensile strength, elongation, and toughness of the nylon 6 non-woven fiber mats electrospun from $20 \mathrm{wt} \%$ and $10 \mathrm{wt} \%$ solutions increased $26 \%, 28 \%$, and $68 \%$ compared with those from $20 \mathrm{wt} \%$ solutions. Young's modulus, tensile strength, elongation, and toughness of nylon 6 non-woven fiber mats electrospun from $20 \mathrm{wt} \%$ and $10 \mathrm{wt} \%$ solutions before and after annealing are summarized in Table 2. For random-laid non-woven fiber mats, once the web is formed, the fibers must be bonded together to stabilize the web and allow it to exhibit the desired mechanical properties. Both individual fiber mechanical properties and cohesion between fibers can be improved by free and constrained annealing of the electrospun non-woven fiber mats at temperatures slightly greater than the base polymer's glass transition temperature. The annealing process reduced internal stresses (decrease shrinkage) and increased crystallinity and crystalline alignment within fibers. Choi et al. [22] reported that the physical properties of the electrospun poly(etherimide) (PEI) fiber web were improved by thermal treatment above its glass transition temperature.

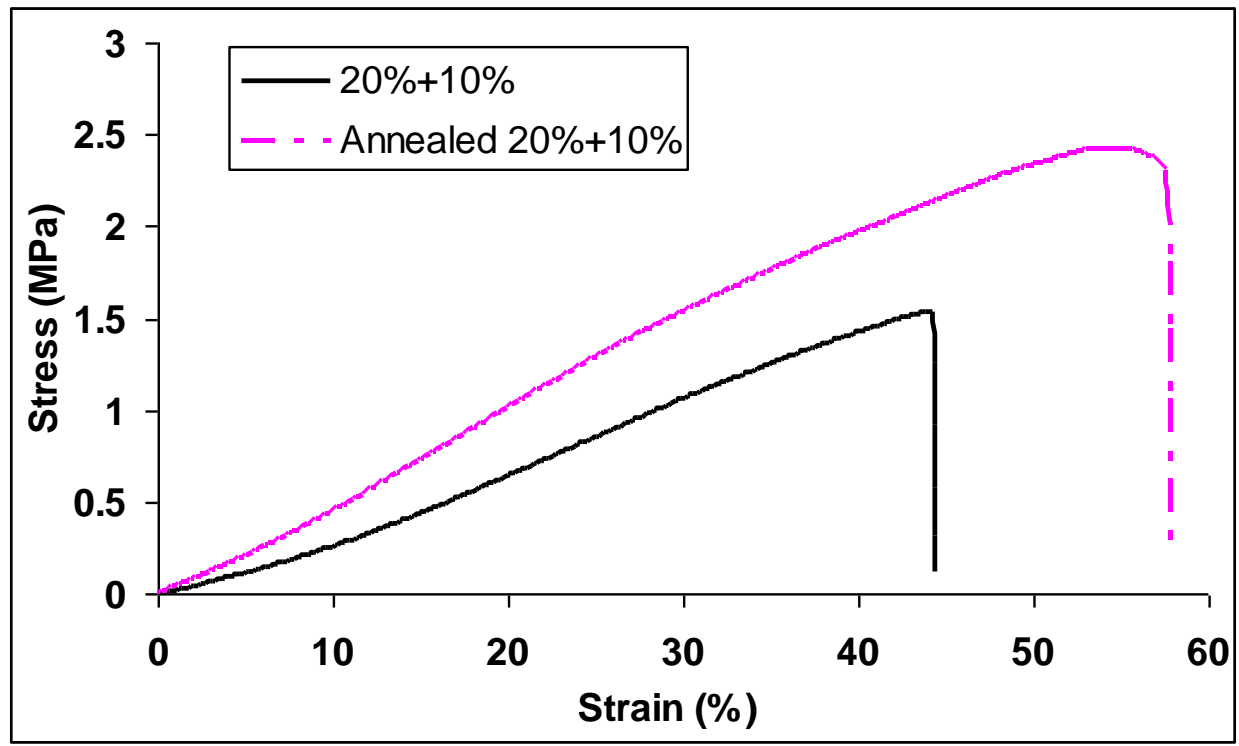

Figure 4. Typical stress-strain plots of nylon 6 non-woven fiber mats electrospun from $20 \mathrm{wt} \%$ and $10 \mathrm{wt} \%$ solutions before and after annealing at $70^{\circ} \mathrm{C}$ for $24 \mathrm{~h}$. 
Table 2. Tensile properties of nylon 6 non-woven fiber mats electrospun from $20 \mathrm{wt} \%$ and $10 \mathrm{wt} \%$ solutions before and after annealing at $70^{\circ} \mathrm{C}$ for $24 \mathrm{~h}$.

\begin{tabular}{ccc}
\hline Tensile Properties & Before Annealing & After Annealing \\
\hline Young's modulus (MPa) & $4.81 \pm 1.03$ & $4.12 \pm 1.33$ \\
Tensile strength (MPa) & $1.63 \pm 0.50$ & $2.06 \pm 0.72$ \\
Elongation $(\%)$ & $45.6 \pm 13.2$ & $58.2 \pm 11.4$ \\
Toughness $(\mathrm{MPa})$ & $0.41 \pm 0.23$ & $0.69 \pm 0.30$ \\
\hline
\end{tabular}

\subsubsection{Solvent Bonding Effect}

Figure 5 shows the typical stress-strain plots of nylon 6 non-woven fiber mats electrospun from $20 \mathrm{wt} \%$ solutions before and after $30 \mathrm{~min}$ formic acid vapor exposure at room temperature. Young's modulus, tensile strength, and toughness of the nylon 6 non-woven fiber mats increased $56 \%, 67 \%$, and $39 \%$, respectively, after formic acid vapor exposure for $30 \mathrm{~min}$ at room temperature. The tensile properties are summarized in Table 3. SEM images in Figure 6 show evidence that the fiber-fiber bonding increased after vapor exposure. Hence, the mechanical properties improved. Distinct bonding points are formed where droplets of formic acid vapor have condensed on the non-woven fabric surface. The higher magnification image of one bonded region shows clear evidence of fusion points between overlapping fibers.

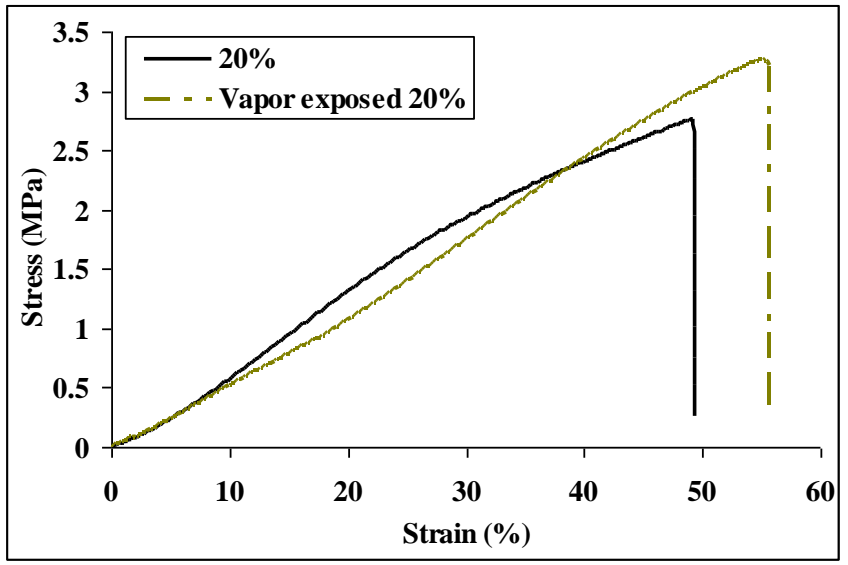

Figure 5. Typical stress-strain plots of nylon 6 non-woven fiber mats electrospun from $20 \mathrm{wt} \%$ solutions before and after formic acid vapor exposure for $30 \mathrm{~min}$ at room temperature.

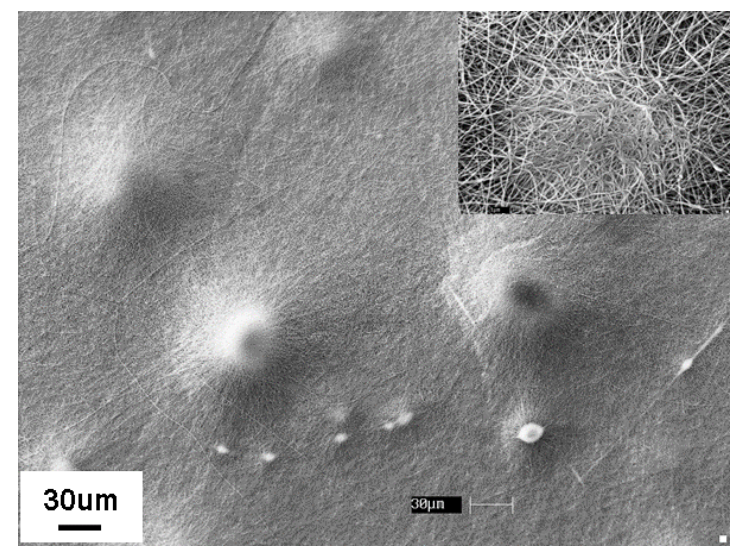

Figure 6. SEM imaging of nylon 6 non-woven fiber mats electrospun from $20 \mathrm{wt} \%$ solutions after formic acid vapor exposure for $30 \mathrm{~min}$ at room temperature. 
Table 3. Tensile properties of nylon 6 non-woven fiber mats electrospun from $20 \mathrm{wt} \%$ solutions before and after formic acid vapor exposure for $30 \mathrm{~min}$ at room temperature.

\begin{tabular}{ccc}
\hline Tensile Properties & Before Exposure & After Exposure \\
\hline Young's modulus $(\mathrm{MPa})$ & $4.81 \pm 1.03$ & $7.50 \pm 2.41$ \\
Tensile strength $(\mathrm{MPa})$ & $2.03 \pm 0.99$ & $3.40 \pm 1.26$ \\
Elongation $(\%)$ & $54.1 \pm 14.6$ & $48.1 \pm 8.9$ \\
Toughness $(\mathrm{MPa})$ & $0.64 \pm 0.48$ & $0.89 \pm 0.55$ \\
\hline
\end{tabular}

We have proved that Young's modulus, tensile strength, and toughness of the nylon 6 non-woven fiber mats increased $51 \%, 87 \%$, and $136 \%$, respectively, after incorporating $1 \mathrm{wt} \%$ CNTs into the nylon 6 nanofibers. This increase was attributed to increased fiber mechanical properties. After exposing the nylon 6 non-woven fiber mats (no CNTs) to formic acid vapor for $30 \mathrm{~min}$ at room temperature, Young's modulus, tensile strength, and toughness of the nylon 6 non-woven fiber mats increased $56 \%, 67 \%$, and $39 \%$, respectively, based on increased fiber-fiber bonding. Figure 7 shows the typical stress-strain plots of nylon 6 non-woven fiber mats electrospun from $20 \mathrm{wt} \%$ solutions and non-woven fiber mats electrospun from $20 \mathrm{wt} \%$ with $1 \mathrm{wt} \% \mathrm{CNTs}$ after vapor exposure. The tensile properties are summarized in Table 4 . Figure 8 shows the comparison of the mechanical properties of these two non-woven fiber mats. Young's modulus of the nylon 6 non-woven fiber mats electrospun from $20 \mathrm{wt} \%$ with $1 \mathrm{wt} \%$ CNTs after vapor exposure was increased $106 \%$, which is the addition of the increase by incorporating CNTs into nylon 6 nanofibers and by vapor exposure. The improvement of mechanical properties of nylon 6 is significant.

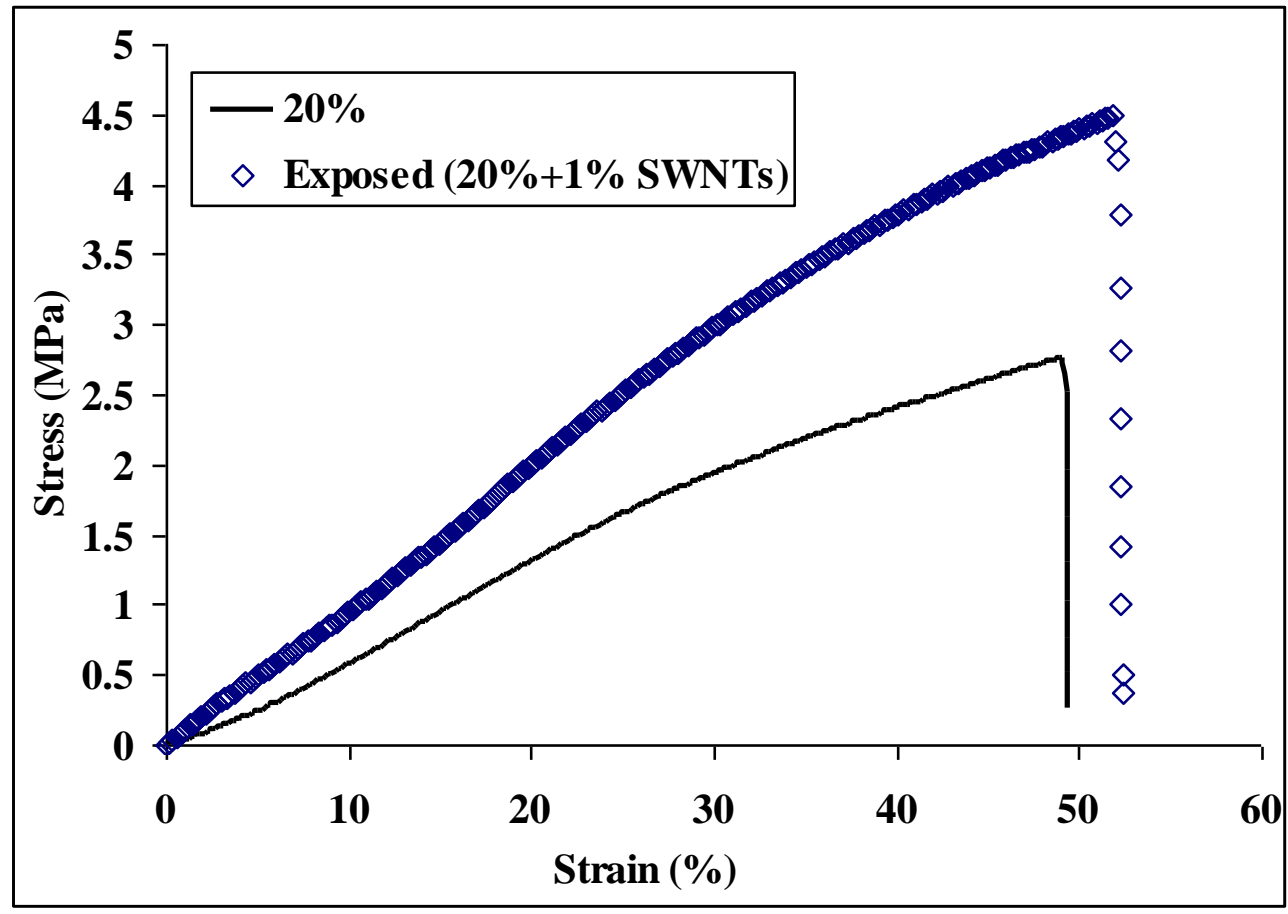

Figure 7. Typical stress-strain plots of nylon 6 non-woven fiber mats electrospun from $20 \mathrm{wt} \%$, and $20 \mathrm{wt} \%$ with $1 \mathrm{wt} \%$ CNTs after formic acid vapor exposure for $30 \mathrm{~min}$ at room temperature. 


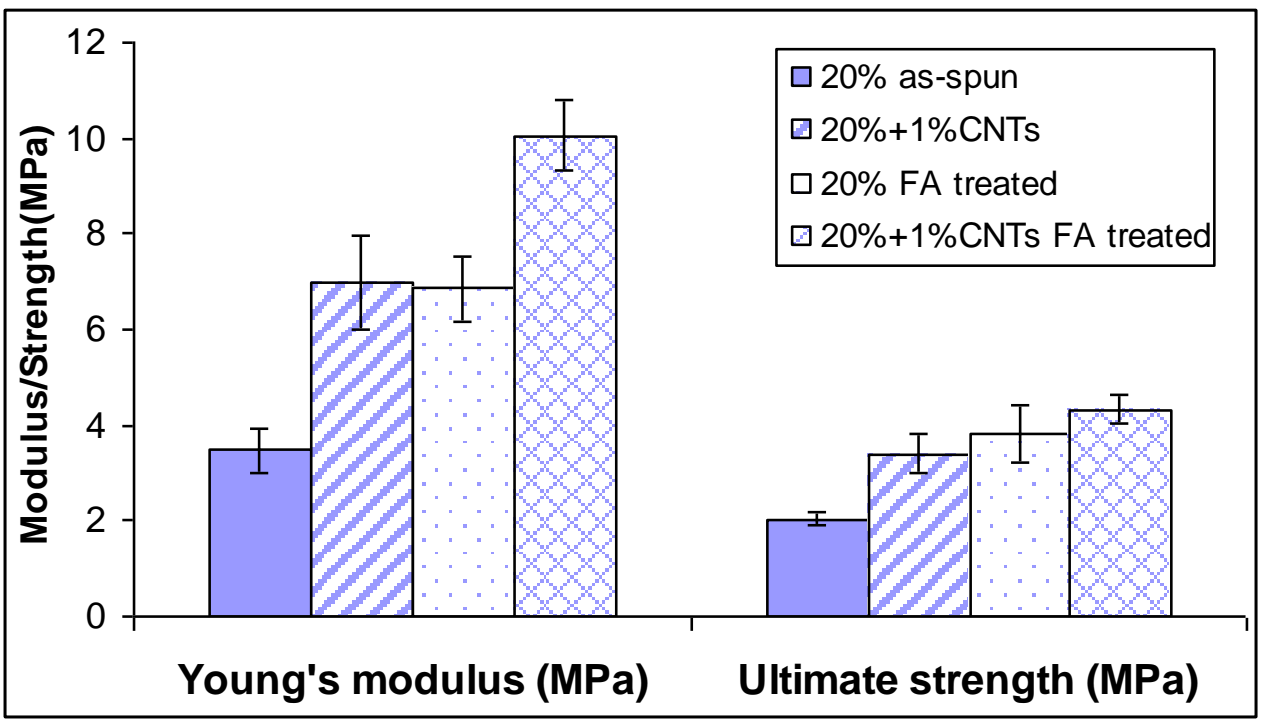

Figure 8. Mechanical properties of nylon 6 non-woven fiber mats electrospun from $20 \mathrm{wt} \%$ solutions and $20 \mathrm{wt} \%$ nylon 6 solutions with $1 \mathrm{wt} \%$ CNTs before/after formic acid vapor exposure for $30 \mathrm{~min}$ at room temperature.

Table 4. Tensile properties of nylon 6 non-woven fiber mats electrospun from $20 \mathrm{wt} \%$ solutions, and from $20 \mathrm{wt} \%$ nylon 6 solution with $1 \mathrm{wt} \%$ CNTs after formic acid vapor exposure for $30 \mathrm{~min}$ at room temperature.

\begin{tabular}{ccc}
\hline Tensile Properties & $\mathbf{2 0} \%$ & Exposed $(\mathbf{2 0} \% \mathbf{+ 1} \mathbf{1} \mathbf{C N T s})$ \\
\hline Young's modulus (MPa) & $4.81 \pm 1.03$ & $9.90 \pm 2.20$ \\
Tensile strength (MPa) & $2.03 \pm 0.99$ & $4.33 \pm 0.94$ \\
Elongation $(\%)$ & $54.1 \pm 14.6$ & $50.0 \pm 4.7$ \\
Toughness (MPa) & $0.64 \pm 0.48$ & $1.25 \pm 0.36$ \\
\hline
\end{tabular}

\subsection{Increase Packing Density of Electrospun Nylon 6 Non-Woven Fiber Mats to Increase Mechanical Properties}

A final approach for increasing the 2-D-structured electrospun nylon 6 non-woven fiber mat's strength was to increase the packing density of fibers by decreasing the fiber diameter. Figure 9 shows the morphology of nylon 6 fibers electrospun from $15 \mathrm{wt} \%$ (Figure 9a) and $20 \mathrm{wt} \%$ (Figure 9b) nylon 6 in $88 \%$ formic acid. Thirty measurements were conducted to analyze the average fiber diameter for using software Image J. The average diameter of nylon 6 fibers electrospun from $20 \mathrm{wt} \%$ and $15 \mathrm{wt} \%$ solutions is $657 \pm 332 \mathrm{~nm}$ (Figure 9d) and $64 \pm 26 \mathrm{~nm}$ (Figure 9c), respectively. Thin but beaded fibers were formed from the $15 \mathrm{wt} \%$ solution. The average fiber diameter of the nylon 6 nanofiber electrospun from $20 \mathrm{wt} \%$ solutions is much bigger than the nylon 6 fibers electrospun from a $15 \mathrm{wt} \%$ solution. Higher concentration of nylon 6 favored the formation of uniform fibers.

To fully realize the theoretically predicted performance improvement, a number of important factors must be manifested in the final composite [10]. For a structural point of view, the fiber spacing should be smaller than the characteristic strength-limiting flaw; thus, smaller fiber diameters are desirable in order to produce a higher packing density. Figure 10 shows the typical stress-strain plots of nylon 6 non-woven fiber mats electrospun from $20 \mathrm{wt} \%$ and $20 \mathrm{wt} \%+15 \mathrm{wt} \%$ solutions. Young's modulus, tensile strength, elongation, and toughness of the non-woven fiber mats are summarized in Table 5. The elongation and toughness of the nylon 6 non-woven fiber mats electrospun from $20 \mathrm{wt} \%$ and $15 \mathrm{wt} \%$ solutions increased $39 \%$ and $75 \%$, respectively, compared to the non-woven fiber mats electrospun from $20 \mathrm{wt} \%$. The smaller size diameter of the nylon 6 nanofibers electrospun from $15 \mathrm{wt} \%$ solutions caused a higher packing density and hence improved the ductility of the electrospun nylon 6 non-woven fiber mats. Papkov et al. [13] has demonstrated improvements in 
modulus and strength of individual electrospun polymer nanofibers with a reduction in their fiber diameter. This size effect of nanofiber diameter to the mechanical properties has also been proved in this study. The non-woven fiber mats electrospun from $20 \mathrm{wt} \%$ and $15 \mathrm{wt} \%$ of solutions showed higher mechanical properties than those from $20 \mathrm{wt} \%$ solutions.

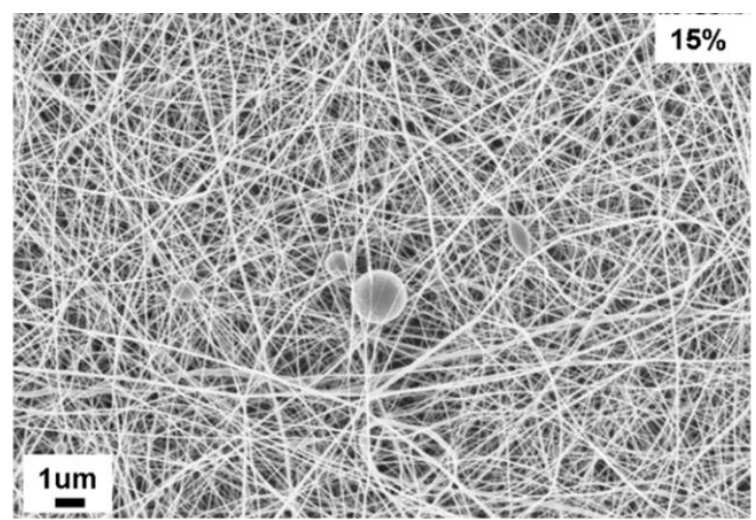

(a)

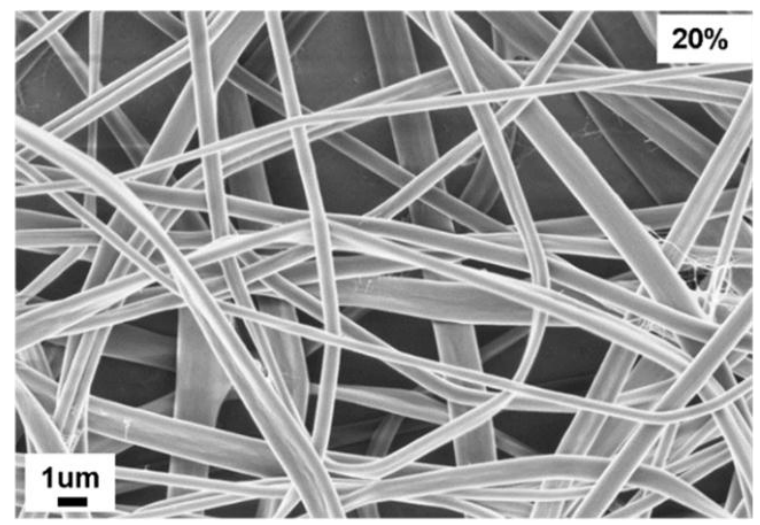

(b)
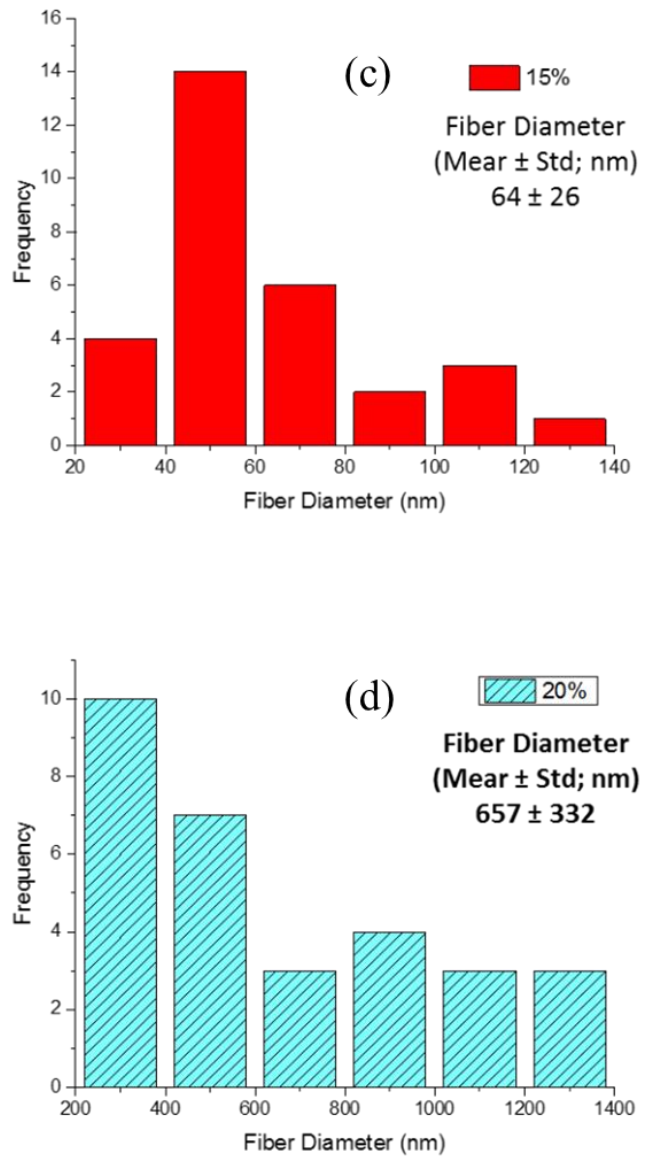

Figure 9. Field emission scanning electron microscope (FESEM) imaging of nylon 6 fibers electrospun from: (a) $15 \mathrm{wt} \%$ nylon 6 in 88\% formic acid solutions; (b) $20 \mathrm{wt} \%$ nylon 6 in $88 \%$ formic acid solutions; (c) fiber diameter distribution from FESEM image (a) of nylon 6 electrospun from $15 \mathrm{wt} \%$ solutions; and (d) fiber diameter distribution from FESEM image (b) of nylon 6 electrospun from $20 \mathrm{wt} \%$ solutions.

Table 5. Tensile properties of nylon 6 non-woven fiber mats electrospun from $20 \mathrm{wt} \%, 20 \mathrm{wt} \%$, and $15 \mathrm{wt} \%$ solutions.

\begin{tabular}{ccc}
\hline Tensile Properties & $\mathbf{2 0 \%}$ & $\mathbf{2 0} \% \mathbf{+ 1 5 \%}$ \\
\hline Young's modulus (MPa) & $4.81 \pm 1.72$ & $4.48 \pm 1.65$ \\
Tensile strength (MPa) & $2.03 \pm 0.99$ & $2.59 \pm 1.25$ \\
Elongation (\%) & $54.1 \pm 14.6$ & $75.4 \pm 12.2$ \\
Toughness (MPa) & $0.64 \pm 0.48$ & $1.12 \pm 0.77$ \\
\hline
\end{tabular}




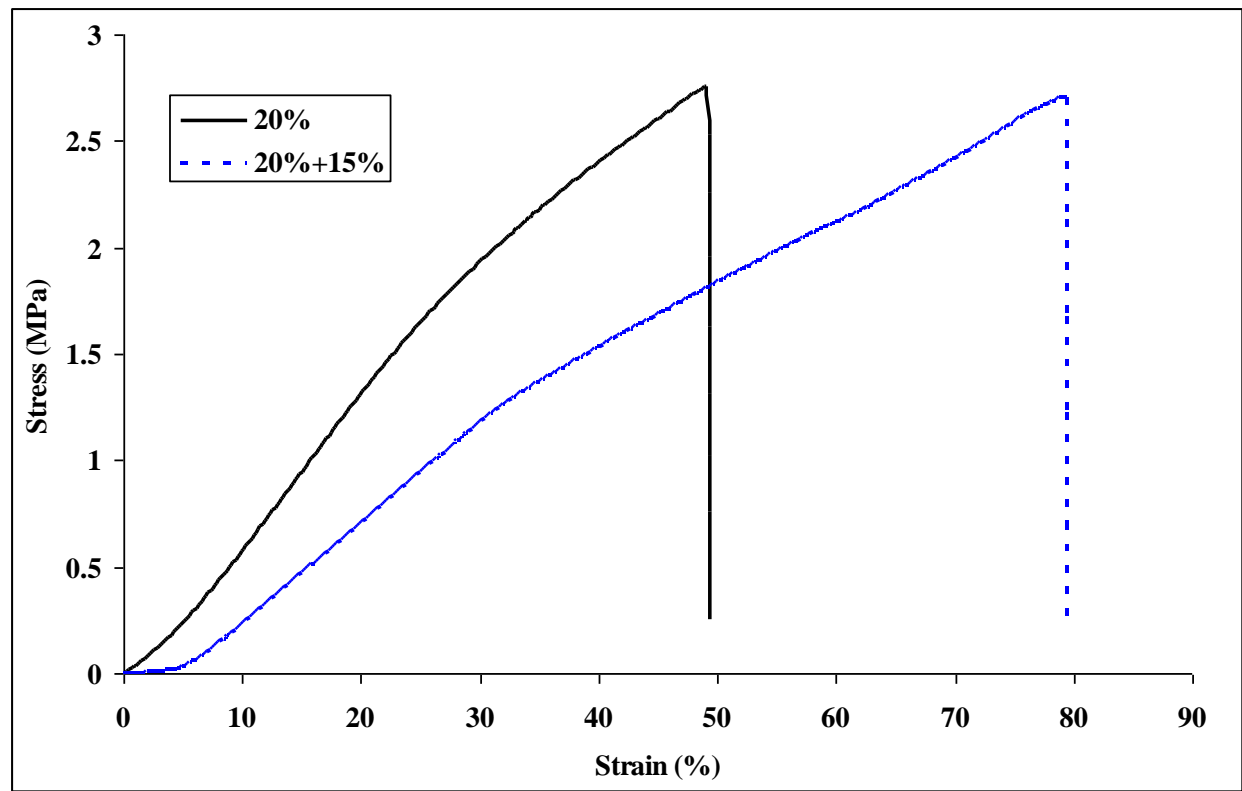

Figure 10. Typical stress-strain plots for the nylon 6 non-woven fiber mats electrospun from $20 \mathrm{wt} \%$, $20 \mathrm{wt} \%$ and $15 \mathrm{wt} \%$ nylon 6 in $88 \%$ formic acid solutions.

\section{Materials and Methods}

\subsection{Materials}

Nylon $6\left(M_{\mathrm{W}}=\sim 10,000 \mathrm{Da}\right)$ and $88 \%$ formic acid were purchased from Sigma-Aldrich (St. Louis, MO, USA) and VWR International (Radnor, PA, USA), respectively. Single-walled Carbon Nanotubes (CNTs) was obtained from Cheap Tubes Inc. (Cambridgeport, VT, USA). All materials were used as received.

\subsection{Preparation of Electrospun Solutions}

Nylon 6 was dissolved in 88\% formic acid at concentrations of $10 \mathrm{wt} \%, 15 \mathrm{wt} \%$, and $20 \mathrm{wt} \%$ with a wrist-action shaker (Burrell Scientific Inc., Pittsburgh, PA, USA) for $24 \mathrm{~h}$ prior to electrospinning. One percent (based on the weight of nylon 6) of CNTs was added to the $15 \mathrm{wt} \%$ and $20 \mathrm{wt} \%$ nylon 6 /formic acid solutions and mixed with the wrist-action shaker for $24 \mathrm{~h}$ before electrospinning.

\subsection{Electrospinning}

A horizontal paralleled (two syringes working at the same time) electrospinning setup (Figure 11) was used in this work. During electrospinning, the nylon 6 solutions were introduced into two 5-mL plastic syringes (VWR Scientific, West Chester, PA, USA). Each syringe was attached to a 20-gauge needle (Hamilton 90020, VWR Inc.) collected to a high voltage supply (Gamma Model ES30, Ormond Beach, FL, USA), with a $25 \mathrm{kV}$ voltage. The needle-to-collector distance was $10 \mathrm{~cm}$. The applied electrical difference was 25,000 volts. The solution was fed at a rate of $0.5 \mathrm{~mL} / \mathrm{h}$ using a syringe pump (Harvard apparatus pump 33, Holliston, MA, USA). The grounded collector was a rotating roll covered with aluminum foil. The samples were collected for three hours. 


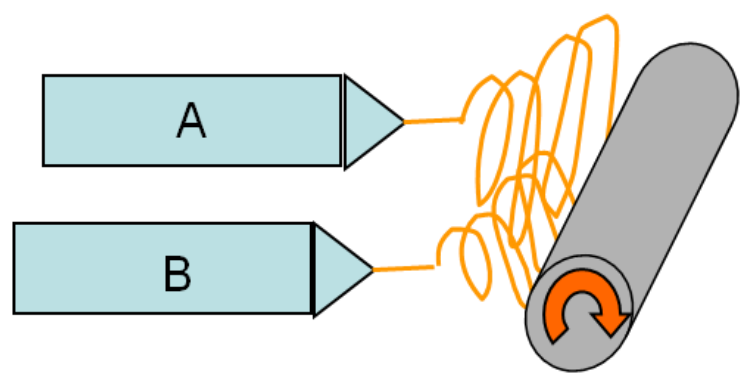

Figure 11. Schematic for horizontal paralleled electrospinning setup.

Table 6 shows the concentrations of the nylon 6 solutions used for the parallel electrospinning (Figure 11). For the non-woven fiber mats electrospun from $20 \mathrm{wt} \%$ and $15 \mathrm{wt} \%, 20 \mathrm{wt} \%$ and $10 \mathrm{wt} \%$, $15 \mathrm{wt} \%$ and $10 \mathrm{wt} \%$ solutions, the syringes A and B shown in Figure 11 were switched at the halfway point of the 3-h electrospinning.

Table 6. The concentrations of the nylon 6 solutions used for parallel electrospinning.

\begin{tabular}{ccc}
\hline A & B & Feed Rate (mL/h) \\
\hline $20 \%$ & $20 \%$ & 0.5 \\
$20 \%$ & $15 \%$ & 0.5 \\
$20 \%$ & $10 \%$ & 0.5 \\
$15 \%$ & $15 \%$ & 0.5 \\
$15 \%$ & $10 \%$ & 0.5 \\
\hline
\end{tabular}

\subsection{Post Treatment of Electrospun Nylon 6 Non-Woven Fiber Mats}

Thermal bonding of the electrospun nylon 6 non-woven fiber mats was achieved by free anneal at $70{ }^{\circ} \mathrm{C}$ for $24 \mathrm{~h}$. To achieve solvent bonding, the electrospun nylon 6 non-woven fiber mats were laid on top of a fiberglass mesh $(20 \times 20$ mesh), which covered a 250 -mL beaker containing $100 \mathrm{~mL}$ formic acid for $30 \mathrm{~min}$ at room temperature.

\subsection{Scanning Electron Microscopy}

Examination of the morphology and fiber diameters of the electrospun nylon 6 non-woven fiber mats was done using a Leica 440 scanning electron microscope (SEM, Leica Microsystems Inc., Buffalo Grove, IL, USA) at $30 \mathrm{kV}$, and a LEO 1550 Field Emission Scanning Electron Microscope (FESEM, Carl Zeiss AG, Oberkochen, Germany) at a voltage of $3 \mathrm{kV}$, using an in-lens detector. Samples were coated for $30 \mathrm{~s}$ with $10 \mathrm{~nm}$ Au-Pd to prevent charging.

\subsection{Mechanical Testing}

The mechanical testing was conducted according to ASTM standard D638-14 [23] with an Instron 5566 (INSTRON, Boston, MA, USA) equipped with a $100-\mathrm{N}$ load-cell at $65 \% \mathrm{RH}$ and $23^{\circ} \mathrm{C}$. The test measures the Young's modulus, tensile stress at break, and tensile strain at break that the electrospun nylon 6 non-woven fiber mats can survive prior to failure. The thickness of the nylon 6 non-woven fiber mats was measured with a micrometer. The crosshead speed was $10 \mathrm{~mm} / \mathrm{min}$. The electrospun nylon 6 non-woven fiber mats were punched into dog-bone specimens with a dimension of $63.5 \times 9.53 \mathrm{~mm}^{2}$ (Die ASTM D-638 type V [23], ODC Tooling \& Molds, Batavia, IL, USA) using a manual test specimen cutting clicker press (Lucris MA Series 3, Toronto, ON, Canada).

\section{Conclusions}

Young's modulus, tensile strength, and toughness of the nylon 6 non-woven fiber mats electrospun from $20 \mathrm{wt} \%$ solutions increased $51 \%, 87 \%$, and 136\%, respectively, after incorporating $1 \mathrm{wt} \%$ CNTs 
into the nylon 6 nanofibers. With the addition of beaded nylon 6 nanofibers into the non-woven fiber mats, the nylon 6 non-woven fiber mats electrospun from $20 \mathrm{wt} \%$ and $10 \mathrm{wt} \%$ demonstrated a statistically significant increase in Young's modulus when compared with nylon 6 non-woven fiber mats electrospun from $20 \mathrm{wt} \%$. After annealing, tensile strength, elongation and toughness of the nylon 6 non-woven fiber mats electrospun from $20 \mathrm{wt} \%$ and $10 \mathrm{wt} \%$ solutions increased $26 \%, 28 \%$, and $68 \%$ compared to those from $20 \mathrm{wt} \%$ solutions. Young's modulus, tensile strength, and toughness of the nylon 6 non-woven fiber mats increased 56\%, 67\%, and 39\%, respectively, after formic acid vapor exposure for $30 \mathrm{~min}$ at room temperature. The smaller size diameter of the nylon 6 nanofibers electrospun from $15 \mathrm{wt} \%$ solutions caused a higher packing density, and hence improved the ductility of the electrospun nylon 6 non-woven fiber mats.

Acknowledgments: This research was supported by Xerox Corporation. This work made use of the Cornell Center for Materials Research Shared Facilities which are supported through the NSF MRSEC program (DMR-1120296).

Author Contributions: Chunhui Xiang and Margaret W. Frey conceived and designed the experiments; Chunhui Xiang performed the experiments; Chunhui Xiang and Margaret W. Frey wrote the paper.

Conflicts of Interest: The authors declare no conflict of interest.

\section{References}

1. Tanioka, A.; Matsumoto, H.; Tsuboi, K. Electrospun nanofiber networks for electronics and optics. MRS Proc. 2009. [CrossRef]

2. Mao, X.; Simeon, F.; Rutledge, G.C.; Hatton, T.A. Electrospun carbon nanofiber (CNF) webs with controlled density of states (DOS) for sensor applications. Adv. Mater. Weinh. Ger. 2013, 25, 1309-1314. [CrossRef] [PubMed]

3. Xiang, C.; Taylor, A.G.; Hinestroza, J.P.; Frey, M.W. Controlled release of nonionic compounds from poly(lactic acid)/cellulose nanocrystal nanocomposite fibers. J. Appl. Polym. Sci. 2013, 127, 79-86. [CrossRef]

4. He, W.; Horn, S.W.; Hussain, M.D. Improved bioavailability of orally administered mifepristone from PLGA nanoparticles. Int. J. Pharm. 2007, 334, 173-178. [CrossRef] [PubMed]

5. Vargas, E.A.T.; do Vale Baracho, N.C.; de Brito, J.; de Queiroz, A.A. Hyperbranched polyglycerol electrospun nanofibers for wound dressing applications. Acta Biomater. 2010, 6, 1069-1078. [CrossRef] [PubMed]

6. Kenawy, E.-R.; Bowlin, G.L.; Mansfield, K.; Layman, J.; Simpson, D.G.; Sanders, E.H.; Wnek, G.E. Release of tetracycline hydrochloride from electrospun poly(ethylene-co-vinylacetate), poly(lactic acid), and a blend. J. Control. Release 2002, 81, 57-64. [CrossRef]

7. Kattamuri, N.; Shin, J.H.; Kang, B.; Lee, C.G.; Lee, J.K.; Suang, C. Development and surface characterization of positively charged filters. J. Mater. Sci. 2005, 40, 4531-4539. [CrossRef]

8. Faccini, M.; Vaquero, C.; Amantia, D. Development of protective clothing against nanoparticle based on electrospun nanofibers. J. Nanomater. 2012, 2012. [CrossRef]

9. Park, J.H.; Kim, B.S.; Yoo, Y.C.; Khil, M.S.; Kim, H.Y. Enhanced mechanical properties of multilayer nano-coated electrospun nylon 6 fibers via a layer-by-layer self-assembly. J. Appl. Polym. Sci. 2008, 107, 2211-2216. [CrossRef]

10. Backer, S.; Petterson, D.R. Some principles of nonwoven fabrics1. Text. Res. J. 1960, 30, 704-711. [CrossRef]

11. Li, L.; Bellan, L.M.; Craighead, H.G.; Frey, M.W. Formation and properties of nylon-6 and nylon-6/montmorillonite composite nanofibers. Polymer 2006, 47, 6208-6217. [CrossRef]

12. Li, L.; Frey, M.W.; Green, T.B. Modification of air filter media with nylon-6 nanofibers. J. Eng. Fibers Fabr. 2006, 1, 1-23.

13. Papkov, D.; Zou, Y.; Andalib, M.N.; Goponenko, A.; Cheng, S.Z.D.; Dzenis, Y.A. Simultaneously strong and tough ultrafine continuous nanofibers. ACS Nano 2013, 7, 3324-3331. [CrossRef] [PubMed]

14. Lee, K.H.; Kin, H.Y.; Ryu, Y.J.; Kim, K.W.; Choi, S.W. Mechanical behavior of electrospun fiber mats of poly(vinyl chloride)/polyurethane polyblends. J. Polym. Sci. Part B Polym. Phys. 2003, 41, 1256-1262. [CrossRef]

15. Kim, H.S.; Jin, H.-J.; Myung, S.J.; Chin, I.-J. Carbon nanotube-adsorbed electrospun nanofibrous membranes of nylon 6. Macromol. Rapid Commun. 2006, 27, 146-151. [CrossRef] 
16. Kim, H.-S.; Chae, Y.S.; Park, B.H.; Yoon, J.-S.; Kang, M.; Jin, H.-J. Thermal and electrical conductivity of poly(L-lactide)/multiwalled carbon nanotube nanocomposites. Curr. Appl. Phys. 2008, 8, 803-806. [CrossRef]

17. Qian, D.; Dickey, E.C.; Andrews, R.; Rantell, T. Load transfer and deformation mechanisms in carbon nanotube-polystyrene composites. Appl. Phys. Lett. 2000, 76, 2868-2870. [CrossRef]

18. Mahfuz, H.; Adnan, A.; Rangari, V.K.; Hasan, M.M.; Jeelani, S.; Wright, W.J.; DeTeresa, S.J. Enhancement of strength and stiffness of nylon 6 filaments through carbon nanotubes reinforcement. Appl. Phys. Lett. 2006, 88. [CrossRef]

19. Bazbouz, M.B.; Stylios, G.K. The tensile properties of electrospun nylon 6 single nanofibers. J. Polym. Sci. B Polym. Phys. 2010, 48, 1719-1731. [CrossRef]

20. Jeong, J.S.; Moon, J.S.; Jeon, S.Y.; Park, J.H.; Alegaonkar, P.S.; Yoo, J.B. Mechanical properties of electrospun PVA/MWNTs composite nanofibers. Thin Solid Films 2007, 515, 5136-5141. [CrossRef]

21. You, Y.; Lee, S.W.; Lee, S.H.; Park, W.H. Thermal interfiber bonding of electrospun poly(L-lactic acid) nanofibers. Mater. Lett. 2006, 60, 1331-1333. [CrossRef]

22. Choi, S.S.; Lee, S.G.; Joo, C.W.; Im, S.S.; Kim, S.H. Formation of interfiber bonding in electrospun poly(etherimide) nanofiber web. J. Mater. Sci. 2004, 39, 1511-1513. [CrossRef]

23. Standard Test Method for Tensile Properties of Plastics; ASTM D 638-14; American Society of Testing and Materials: West Conshohocken, PA, USA, 2014.

(C) 2016 by the authors; licensee MDPI, Basel, Switzerland. This article is an open access article distributed under the terms and conditions of the Creative Commons by Attribution (CC-BY) license (http:/ / creativecommons.org/licenses/by/4.0/). 